\title{
Expanding the operating space of ICRF on JET with a view to ITER
}

P.U. Lamalle 1a), M.J. Mantsinen 2a), J.-M. Noterdaeme 3,14), B. Alper 4), P. Beaumont 4), L.

Bertalot 5a), T. Blackman 4), Vl.V. Bobkov 3), G. Bonheure 1a), J. Brzozowski 8), C. Castaldo 5a), S. Conroy 8), M. de Baar 9), E. de la Luna 6), P. de Vries 4), F. Durodié 1a), G. Ericsson 8b), L.-G. Eriksson 7), C. Gowers 4), R. Felton 4), J. Heikkinen 2b), T. Hellsten 8a), V. Kiptily 4), K. Lawson 4), M. Laxåback 8a), E. Lerche 1a), P. Lomas 4), A. Lyssoivan 1a), M.-L. Mayoral 4), F. Meo 10), M. Mironov 11), I. Monakhov 4), I. Nunes 12), G. Piazza 13), S. Popovichev 4), A. Salmi 2a), M.I.K. Santala 2a), S. Sharapov 4), T. Tala 2b), M. Tardocchi 5b), D. Van Eester 1a), B. Weyssow 1b) and JET EFDA contributors*

1) Association EURATOM - Belgian Stateł, Brussels, Belgium: a) Plasma Physics Laboratory, Royal Military Academy, 30 av. de la Renaissance; b) PTM-ULB.

2) Association EURATOM-Tekes, a) HUT / b) VTT, Helsinki, Finland.

3) Max-Planck IPP-EURATOM Assoziation, Garching, Germany.

4) EURATOM/UKAEA Fusion Association, Culham Science Centre, Abingdon, U.K.

5) Associazione EURATOM-ENEA sulla Fusione, ${ }^{\mathrm{a} F r a s c a t i} /{ }^{\mathrm{b}} \mathrm{CNR}$ Milano, Italy.

6) Asociación EURATOM-CIEMAT, Laboratorio Nacional de Fusion, Spain.

\footnotetext{
* See annex of J. Pamela et al., in Fusion Energy 2004 (Proc. 20 ${ }^{\text {th }}$ Int. Conf., Vilamoura, 2004) (Vienna: IAEA) CD-ROM file OV/1-X.
} 
7) Association EURATOM-CEA, CEA/DSM/DRFC, CEA Cadarache, F-13108 St Paul lez Durance, France.

8) Association VR-EURATOM, Sweden: a) Alfvén Laboratory; b) Uppsala University.

9) FOM-Rijnhuizen, Association EURATOM-FOM\$, Nieuwegein, The Netherlands.

10) Ris $\varnothing$, Association EURATOM-Denmark, Kopenhagen, Denmark.

11) Ioffe Physico-Technical Institute, St Petersburg, Russia.

12) Associação EURATOM-IST, Instituto Superior Técnico, Portugal.

13) Forschungszentrum Karlsruhe, IKET, Germany.

14) Gent University, EESA, Belgium. $\quad \ddagger$ Partners in the Trilateral Euregio Cluster (TEC).

${ }^{\ddagger}$ This paper is an expanded version of material originally presented at the $20^{\text {th }}$ IAEA Fusion Energy Conference, Vilamoura, Portugal, 1-6 November 2004 (Fusion Energy 2004, Vienna: IAEA), CDROM file EX/P4-26. 


\section{Abstract}

This paper reports on ITER-relevant ICRF physics investigated on JET in 2003 and early 2004. Minority heating of helium three in hydrogen plasmas - $\left({ }^{3} \mathrm{He}\right) \mathrm{H}-$ was systematically explored by varying the ${ }^{3} \mathrm{He}$ concentration and the toroidal phasing of the antenna arrays. The best heating performance (a maximum electron temperature of $6.2 \mathrm{keV}$ with 5MW of ICRF power) was obtained with a preferential wave launch in the direction of the plasma current. A clear experimental demonstration was made of the sharp and reproducible transition to the mode conversion heating regime when the ${ }^{3} \mathrm{He}$ concentration increases above $\sim 2 \%$. In the latter regime the best heating performance (a maximum electron temperature of $8 \mathrm{keV}$ with 5MW of ICRF power) was achieved with dipole array phasing, i.e. a symmetric antenna power spectrum. Minority heating of deuterium in hydrogen plasmas - (D)H - was also investigated but was found inaccessible, because this scenario is too sensitive to impurity ions with $\mathrm{Z} / \mathrm{A}=1 / 2$ such as $\mathrm{C}^{6+}$, small amounts of which directly lead into the mode conversion regime. Minority heating of up to $3 \%$ of tritium in deuterium plasmas was systematically investigated during the JET Trace Tritium experimental campaign (TTE). This required operating JET at its highest possible magnetic field (3.9 to 4T) and the ICRF system at its lowest frequency $(23 \mathrm{MHz})$. The interest of this scenario for ICRF heating at these low concentrations and its efficiency at boosting the suprathermal neutron yield were confirmed, and the measured neutron and gammay ray spectra permit interesting comparisons with advanced ICRF code simulations. Investigations of finite Larmor radius effects on the RF-induced high-energy tails during second harmonic $\left(\omega=2 \omega_{c}\right)$ heating of a hydrogen minority in D plasmas clearly demonstrated a strong decrease of the RF diffusion coefficient at proton energies $\sim 1 \mathrm{MeV}$, in agreement with theoretical 
expectations. Fast wave heating and current drive experiments in deuterium plasmas showed effective direct electron heating with dipole phasing of the antennas, but only small changes of the central plasma current density were observed with the directive phasings, in particular at low single pass damping. New investigations of the heating efficiency of ICRF antennas confirmed its strong dependence on the parallel wavenumber spectrum. Advances in topics of a more technological nature are also summarized: ELM studies using fast RF measurements, the successful experimental demonstration of a new ELM-tolerant antenna matching scheme, and technical enhancements planned on the JET ICRF system for 2006, themselves equally strongly driven by the preparation for ITER. 


\section{Introduction}

The size and capability of the Joint European Torus $\left(\mathrm{JET}^{1},[1]\right)$ to confine very energetic particles, together with its versatile ion cyclotron resonance frequency (ICRF) system, provide a unique environment to develop ICRF techniques relevant to the forthcoming International Tokamak Experimental Reactor ITER [2]. During the JET experimental campaigns of 2003 and early 2004, in addition to further development of ICRF as a tool for the experimental programme, several heating and current drive scenarios have been investigated, contributing to the physics understanding and operational expertise required for successful use of ICRF on ITER. The following sections focus on these advances. Three hitherto scarcely documented 'inverted' minority heating scenarios, in which the minority ions have a smaller charge to mass ratio than the majority ones, have received special attention: section 2 reports on experiments on ICRF heating of helium three $\left({ }^{3} \mathrm{He}\right)$ and deuterium (D) in hydrogen $(\mathrm{H})$ plasmas, which are the scenarios planned for the start-up phase of ITER, and section 3 on minority heating of tritium (T), which would be an attractive scenario when ITER starts using T. Investigations of finite Larmor radius effects on the RF-induced high-energy tails are summarized in section 4, fast wave heating and current drive experiments in section 5 and new results on the heating efficiency of ICRF antenna arrays in section 6. The remainder of the paper reports progress and achievements on topics of a more technical nature: studies of the ELMs using fast RF measurements, experimental demonstration of a new ELM-tolerant antenna matching scheme, and the technical

\footnotetext{
${ }^{1}$ Major radius $\mathrm{R}_{0} \approx 3 \mathrm{~m}$, horizontal plasma minor radius $\approx 1 \mathrm{~m}$, maximum plasma elongation $\approx 2$, ITERrelevant plasma triangularities, maximum toroidal field $4 \mathrm{~T}$ at the magnetic axis, maximum current $5 \mathrm{MA}$ in the present divertor configuration.
} 
enhancements under implementation on the JET ICRF system, themselves likewise strongly driven by the preparation for ITER.

\section{ICRF heating in hydrogen plasmas}

In the start-up phase of ITER, activation will at first be minimized by operating in $\mathrm{H}$ plasmas. The two reference ICRF scenarios, known as $\left({ }^{3} \mathrm{He}\right) \mathrm{H}$ and (D)H, rely on heating minority ${ }^{3} \mathrm{He}$ or D ions at their fundamental cyclotron frequency. In the past very few experiments have been dedicated to these scenarios [3] in which an ion-ion hybrid resonance/cut-off pair of the fast magnetosonic wave is located between the minority cyclotron layer and the antennas. The heating of ${ }^{3} \mathrm{He}$ in $\mathrm{H}$ has now been explored in a sequence of JET discharges at magnetic fields between 3.3 and $3.6 \mathrm{~T}$ and a plasma current of 2MA. The ICRF power was applied at $37 \mathrm{MHz}$, which positions the cyclotron resonance layer $\omega=\omega_{\mathrm{c}}{ }^{3} \mathrm{He}$ in the vicinity of the plasma magnetic axis. The experiments systematically used ICRF power modulation at a frequency of $20 \mathrm{~Hz}$ at the beginning and the end of the RF power flat-top (see Fig. 1), allowing evaluation of the radial profiles of wave absorption by the electrons by means of Fast Fourier Transform (FFT) and break-in-slope (BIS) analysis $[4,5]$ of the electron temperature response. The ${ }^{3} \mathrm{He}$ concentration $\left[{ }^{3} \mathrm{He}\right]=n_{3 \mathrm{He}} / n_{e}$ was varied from below $1 \%$ up to $10 \%$. The expertise developed at JET to estimate and control $\left[{ }^{3} \mathrm{He}\right]$ in real time [5] was put to full use and levels as low as $1.8 \%$ were successfully controlled for the first time. Lower $\left[{ }^{3} \mathrm{He}\right]$ values were obtained by ${ }^{3} \mathrm{He}$ gas puffing before the ICRF heating phase.

The minority heating $(\mathrm{MH})$ regime was observed at low concentrations (up to $\sim 2 \%$ ). Presence of a fast ${ }^{3} \mathrm{He}$ ion population was detected by $(i)$ its contribution to the neutron rate through the nuclear 
reaction ${ }^{9} \mathrm{Be}\left({ }^{3} \mathrm{He}, \mathrm{n}\right){ }^{11} \mathrm{C}$; (ii) gamma-ray spectrometry [6] based on nuclear reactions between energetic ${ }^{3} \mathrm{He},{ }^{9} \mathrm{Be}$ and ${ }^{12} \mathrm{C}$ impurities, and (iii) low- and high-energy neutral particle analysis (NPA) [7]. Fig. 1 shows three discharges with $\left[{ }^{3} \mathrm{He}\right]<1 \%$ and $5 \mathrm{MW}$ of ICRF, each of them using a different toroidal phasing of the JET antenna arrays. The design of these four four-strap ICRF antennas, known as "A2", is described in detail in reference [8]. In dipole $(0 \pi 0 \pi)$ phasing of the strap currents they launch waves with a symmetric toroidal spectrum and dominant peak at toroidal modes $n \approx \pm 27$, which corresponds to dominant toroidal wavenumbers $\mathrm{k}_{\varphi} \approx \pm 6.4 \mathrm{~m}^{-1}$ at the antennas. In ' $+90^{\circ}$ ' and '$90^{\circ}$ ' progressive phasings of the four straps the antennas launch waves propagating dominantly along (co-) and opposite (counter-) the plasma equilibrium current, respectively. The toroidal spectrum has its dominant peak at toroidal modes $n \approx+14$ in $+90^{\circ}$ and $n \approx-14$ in $-90^{\circ}$ phasing, which respectively correspond to dominant toroidal wavenumbers $\mathrm{k}_{\varphi} \approx+3.5$ and $-3.5 \mathrm{~m}^{-1}$ at the antennas. (Note that the design of the ITER ICRF array offers the same flexibility of toroidal phasing.) In the MH regime illustrated FIG. 1 a maximum electron temperature of $6.2 \mathrm{keV}$ was reached with $+90^{\circ}$. Higher neutron rate, fast ${ }^{3} \mathrm{He}$ energy content, NPA flux and $\gamma$-ray emissivity are obtained with $+90^{\circ}$ than with matching discharges in the other phasings. Such behaviour can be explained in terms of an inward fast ion orbit pinch produced by the co-current $+90^{\circ}$ wave spectrum $[9,10]$, for which multiple evidence has previously been accumulated in phased ICRF experiments on JET $[11,12$, $13]$.

As $\left[{ }^{3} \mathrm{He}\right]$ was increased above $2 \%$, a sudden transition was reproducibly observed to the mode conversion (MC) regime, in which the ICRF fast wave converts to a short wavelength mode at the ion-ion hybrid layer, leading to efficient direct electron heating. The first indication of a change in the heating regime was the disappearance of the fast ${ }^{3} \mathrm{He}$ population. The related changes in $\gamma$-ray emission, for which the threshold ${ }^{3} \mathrm{He}$ energy is $0.9 \mathrm{MeV}$, are shown on Fig. 2 for three discharges 
differing only by their $\left[{ }^{3} \mathrm{He}\right]$. In discharge \#63319 with $\left.{ }^{3} \mathrm{He}\right]<1.8 \%$ a high signal was collected throughout. In $\# 63320$, as $\left[{ }^{3} \mathrm{He}\right]$ increased above $2 \%$ at $\approx 6.3 \mathrm{~s}$, the $\gamma$-ray signal began to decrease and finally disappeared. In shot \#63324, almost no signal was collected. Moreover, as $\left[{ }^{3} \mathrm{He}\right]$ increased, the temperature response to the ICRF power modulation gradually changed, indicating a change in power deposition. This is well illustrated by the discharge shown FIG. 3, during which [ $\left.{ }^{3} \mathrm{He}\right]$ was progressively increased from $\sim 0.8$ to $3.2 \%$ and the $20 \mathrm{~Hz}$ power modulation applied throughout the RF pulse. In the MH regime, electron heating takes place indirectly by collisions with fast ions and the period of the ICRF power modulation $(0.05 \mathrm{~s})$ associated with an estimated fast ${ }^{3}$ He slowing- down time of about 0.2 s prevented observation of a clearcut $\mathrm{T}_{\mathrm{e}}$ response (see left part of the figure, $\mathrm{t}<8.3 \mathrm{~s}$ ). In contrast, electron heating in the $\mathrm{MC}$ regime takes place directly by wave Landau damping and a prompter $T_{e}$ response was observed (see right part of the figure, $\mathrm{t}>8.3 \mathrm{~s}$ ). The transition to the MC regime was also confirmed by the FFT and BIS analyses which showed the apperance of a narrow electron power deposition profile at the estimated location of the ion-ion hybrid layer. Fig. 4 presents an overview of two discharges in the MC regime $\left(\left[{ }^{3} \mathrm{He}\right] \sim 3.5 \%\right)$ with dipole and $+90^{\circ}$ phasing. In order to maximize the central $\mathrm{T}_{\mathrm{e}}$, the toroidal field was lowered to $3.3 \mathrm{~T}$, positioning the ion-ion hybrid layer at around $\mathrm{R}=2.8 \mathrm{~m}$, slightly inboard of the magnetic axis $\left(\mathrm{R}_{0}=2.96 \mathrm{~m}\right)$. A maximum temperature of $8 \mathrm{keV}$ was obtained with dipole phasing. A comparative code analysis of the two discharges is under way to confirm the difference in dominant $\mathrm{k}_{\mathrm{f}}$ as the origin of the higher temperature obtained in dipole.

In strong contrast with ${ }^{3} \mathrm{He}$, the use of D minority heating in hydrogen plasmas was not successful. This is attributed to the $C^{6+}$ impurity (and contributions from any other impurity with $Z / A=1 / 2$ ), which has the same cyclotron layer as D and influences wave propagation like a sixfold as high number concentration of D. Presence of carbon at levels of 1 to $2 \%$ directly leads into the mode conversion 
regime or can even expel the mode conversion layer from the plasma. This effect virtually rules out the (D)H scenario, leaving $(3 \mathrm{He}) \mathrm{H}$ as the only viable minority heating scenario for the non-active phase of ITER in hydrogen plasmas. This negative result seems to contradict the conclusions of [3] regarding the (D)H scenario on JET, for which a good absorption of power had been reported, on the same level as with the $\left({ }^{3} \mathrm{He}\right) \mathrm{H}$ scenario. The principal difference between our (D)H experiments and the single discharge presented in [3] is the equilibrium magnetic field, which was respectively 3.9 and $3.5 \mathrm{~T}$, leading to deuterium fundamental cyclotron resonance layers around $\mathrm{R}=3.1 \mathrm{~m}$ and $2.85 \mathrm{~m}$, respectively. Two main factors can explain a better wave absorption and a significantly higher antenna loading in the configuration of [3]: (i) If (due to the $\mathrm{C}$ impurity effect described above) the heating regime of [3] was indeed mode conversion instead of the assumed minority heating, the mode conversion layer was closer to the magnetic axis than in our experiments, resulting in more efficient Landau/TTMP damping and better electron heating due to the higher local $\mathrm{T}_{\mathrm{e}}$. (ii) In addition, the ${ }^{3} \mathrm{He}$ cyclotron layer was located at $\mathrm{R} \approx 3.75 \mathrm{~m}$ in the $(\mathrm{D}) \mathrm{H}$ discharge of [3], inside the plasma, whereas it was at $R \approx 4.1 \mathrm{~m}$, just outside the plasma in the 2004 experiments. Parasitic cyclotron absorption by residual ${ }^{3} \mathrm{He}$, which was carefully avoided in 2004 by operating at a higher magnetic field, is likely to have taken place in [3] at a significant level, as njection of ${ }^{3} \mathrm{He}$ gas had been used in earlier discharges on the same day of experiments. This re-interpretation of the discharge appears consistent with the conclusions from the more recent investigations drawn above.

A comprehensive account of the ICRF heating experiments in hydrogen plasmas summarized in this section can be found in [14] and [15]. 


\section{Minority heating of tritium}

Plasmas with low tritium concentration will occur when ITER starts using $T$. In this mode of operation, ICRF minority heating of T at its fundamental cyclotron frequency $\left(\omega=\omega_{\mathrm{cT}}\right)$, which directly accelerates one of the fusion fuel ions, would be a physically attractive heating scenario. On JET its use is technically highly challenging as it requires the highest equilibrium magnetic fields $\left(B_{0}=3.9\right.$ to $4 \mathrm{~T})$ and the lowest available generator frequency $(\sim 23 \mathrm{MHz})$, at which only modest levels of ICRF power $\sim 1.5 \mathrm{MW}$ are available. These extreme parameter values yield the most central $\mathrm{T}$ cyclotron layer achievable on JET, located near $\mathrm{R}=2.5 \mathrm{~m}$, on the high field side of the magnetic axis. The scenario was first very briefly investigated during the JET DTE1 experimental campaign of 1997 [16, 17] with $\sim 5 \% \mathrm{~T}$ and on TFTR [18] with up to $20 \% \mathrm{~T}$. On ITER the scenario lies outside the planned RF system frequency range (currently 40 to $55 \mathrm{MHz}$ ) and would require its extension at low frequencies, down to $\sim 27 \mathrm{MHz}$. Given the technical difficulties to design wide-band ICRF antennas, such an extension would have to be strongly motivated.

The JET Trace Tritium experimental (TTE) campaign $[19,20,21,22]$ provided a rare opportunity for an intensive study of the T minority heating scenario at low concentrations in deuterium plasmas. Tritium was introduced in the discharge by gas puffs resulting in concentrations up to $\sim 3 \%$ (in a few discharges neutral beam $\mathrm{T}$ injection was used instead). Energetic $\mathrm{T}$ tails of 80 to $120 \mathrm{keV}$ were deduced from the neutron emission spectroscopy [23] and gamma ray spectra [6] measurements. The direct acceleration of tritons by ICRF at energies close to the maximum of the D-T reaction rate boosted the DT neutron yield by some three orders of magnitude, and simultaneously provided good bulk electron heating (Fig. 5). The moderate triton tail energies also provide good ion heating (off-axis in the JET configuration). This confirms the scenario as an attractive heating scheme at low 
concentration. Its possible incorporation in the ITER ICRF design should be revisited after further experiments at intermediate $\mathrm{T}$ concentrations, e.g. during a full $\mathrm{D}-\mathrm{T}$ campaign on JET. A comprehensive account of the TFTR discharges cited above would be invaluable for planning such experiments, but does not seem to have been published.

Detailed interpretation and modelling of the ICRF experiments in TTE benefit from the neutron and gamma ray emissivity data, which allow interesting code benchmarks and enhancements. Fig. 6 shows the good agreement found between the high-field-side (HFS) peaking of the 2D neutron emissivity profile and the corresponding fast triton midplane density simulated with the SELFO code [24]. The simulation shows that the profile peaking is due to barely passing tritons; it also correctly estimates the experimental neutron yield and $\mathrm{T}$ tail temperature. In this discharge the tritium fraction $\mathrm{N}_{\mathrm{T}} / \mathrm{N}_{\mathrm{D}}$ was estimated on the order of 1.5 to $2.5 \%$ based on the ratio of D-T to D-D neutron emissivities during diagnostic D neutral beam blips following the ICRF pulse $(9<\mathrm{t}<9.6 \mathrm{~s})$. The SELFO simulation corresponds to a value of $\mathrm{N}_{\mathrm{T}} / \mathrm{N}_{\mathrm{D}}=2 \%$ and assumes a $0.25 \%$ level of beryllium impurity, which results in $48 \%$ of the RF power being absorbed by T, $36 \%$ by Be and the remainder by the electrons. Note that parasitic absorption by Be would be eliminated on ITER by positioning the $\mathrm{T}$ cyclotron layer in the vicinity of the magnetic axis.

During the TTE a few discharges were also dedicated to second cyclotron harmonic heating of tritium $\left(\omega=2 \omega_{\text {ст }}\right.$ at $37 \mathrm{MHz}$ with $\left.\mathrm{B}_{0}=3.7 \mathrm{~T}\right)$. At higher $\mathrm{T}$ concentrations $(50-50 \mathrm{D}-\mathrm{T}$ mix $)$, this is the reference ITER scenario, investigated during the JET DTE1 [17] and the TFTR DT campaign [25]. The goal of the TTE discharges was to study the RF power deposition in the low concentration range (with $\mathrm{N}_{\mathrm{T}} / \mathrm{N}_{\mathrm{D}}$ up to $\sim 3 \%$ ). Fast tritons with energies above $700 \mathrm{keV}$ were observed, as deduced from gamma ray spectra [6]. This scenario is more adapted to higher $\mathrm{T}$ concentrations, harmonic cyclotron damping being a finite Larmor radius effect. Analysis of the discharges is not 
straightforward due to the strongly competing fundamental cyclotron absorption by residual ${ }^{3} \mathrm{He}$. Their detailed interpretation and comparisons with numerical predictions remain to be completed and will be reported in the future.

\section{Finite Larmor radius (FLR) effects on the ICRH minority ion tails at $\omega=2 \omega_{\mathrm{cH}}$}

Wave absorption at the second ion cyclotron harmonic $\left(\omega=2 \omega_{c}\right)$ depends on the ratio of the particle Larmor radius to the wavelength $\lambda_{\perp}$. Theory predicts a maximum absorption when this ratio increases to $\sim 0.3$, followed by a decrease to much smaller levels at higher ratios $\sim 0.6$. This behaviour defines a characteristic particle energy $\mathrm{E}^{*}$ at which the RF quasilinear diffusion coefficient has a first minimum. This absorption-free region acts as a barrier preventing particles from reaching higher energies. At fixed magnetic field, $\mathrm{E}^{*} \propto \lambda_{\perp}^{2}$ is inversely proportional to the density. Minority hydrogen ions were heated at their second cyclotron harmonic $2 \omega_{\mathrm{cH}}$ with 3 to $5 \mathrm{MW}$ of ICRF (51MHz, dipole phasing) in 1.65T, 1.65MA JET deuterium discharges with central electron densities between 3 and $4 \times 10^{19} \mathrm{~m}^{-3}$ (i.e. different wavelengths). Fast hydrogen energy distributions were measured with a high-energy neutral particle analyzer (NPA) [26], which detects protons with energies between 0.28 and $1.1 \mathrm{MeV}$. Note that the JET tokamak is ideally suited to perform this type of experiment which requires confining and diagnosing protons in the $\mathrm{MeV}$ range (In the low magnetic field discharges of the experiment the Larmor radius of $1 \mathrm{MeV}$ protons was up to $\sim 0.09 \mathrm{~m}$, about $10 \%$ of the discharge horizontal minor radius.) Fig. 7 shows that, at similar heating powers per particle, a higher plasma density (hence a lower $\mathrm{E}^{*}$ ) yields a less energetic $\mathrm{H}$ tail with a lower local temperature. Moreover the low energy range $\left(E_{\perp}<0.4 \mathrm{MeV}\right)$ of the distribution function is barely 
affected by the change of density. This is consistent with the above theoretical considerations and provides clear evidence that FLR effects play an important role in determining the shape of the high energy part of the distribution. The observations would indeed not be consistent with the assumption of a constant RF diffusion coefficient at high energy (such as found in the Stix theory of fundamental cyclotron heating [27]): if the diffusion coefficient were constant the high energy distribution function would behave like $\exp \left(-E_{\perp} / k T_{\text {eff }}\right)$ where $E_{\perp}$ is the proton perpendicular energy and $T_{\text {eff }}$ an effective temperature scaling as $T_{e f f} \propto P_{\perp} T_{e}^{3 / 2} /\left(n_{r} N_{e}\right)\left(P_{\perp}\right.$ is the flux-surface-averaged ICRF power absorbed by the protons and $n_{r}$ the density of resonant protons). The discharges presented on Fig. 7 have very similar values of the parameter $T_{\text {eff }}$ (they only differ by $\sim 8 \%$ ), which contradicts the important differences between the measured distribution functions. FIDO [28] code simulations including the high energy FLR effects are in good agreement with the measurements [29].

\section{Fast wave heating and current drive (FWHCD) experiments}

FWHCD has been studied in JET internal transport barrier deuterium plasmas at $\mathrm{B}_{0}=3.4 \mathrm{~T}$ and $\mathrm{RF}$ power up to $6 \mathrm{MW}$ at $\mathrm{f}=37 \mathrm{MHz}$. This is the same $\mathrm{f} / \mathrm{B}_{0}$ ratio as planned for ITER, at which the hydrogen and deuterium fundamental cyclotron layers are both outside the plasma, respectively on the low and high magnetic field sides of the discharge. This section only provides a brief summary of the experiments, and we refer the reader to [30] for a comprehensive account. Traces of residual

${ }^{3} \mathrm{He}$, which has its fundamental cyclotron layer in the plasma in this configuration, absorbed significant RF power, reducing the fraction available for FWHCD via transit time magnetic pumping (TTMP) 
and electron Landau damping (ELD). On ITER similar power diversion is expected from T absorption at $2 \omega_{\text {cт }}$. Despite low wave single pass damping (a few percent), effective direct electron heating was observed in dipole $(0 \pi 0 \pi)$ antenna phasing. In the FWCD experiments with $\pm 90^{\circ}$ antenna phasing the electron heating efficiency was typically $\sim 50 \%$ of that for $0 \pi 0 \pi$ and only small changes of central current density were observed. This is attributed to the competition of parasitic ion absorption, the bng current penetration time, and a large parasitic dissipation associated with RF sheaths, discussed in Section 6.

With the frequency range selected for the ITER ICRF system (currently 40 to $55 \mathrm{MHz}$ ) the absorption by tritium at the second harmonic resonance $\left(\omega=2 \omega_{\mathrm{cT}}\right)$ cannot be avoided. However the single pass damping by TTMP/ELD will be stronger on ITER and hence the competition of parasitic wave absorption by ions less severe than on JET. The stronger single pass damping should also reduce the parasitic absorption at the RF sheaths. On the other hand the characteristic time for changing the current will be even longer than on JET.

\section{New investigations of the ICRF heating efficiency}

In specific operating conditions substantial discrepancies are found between the power $\mathrm{P}_{\mathrm{L}}$ launched by the A2 ICRF antennas and the plasma power balance. The power not accounted for in the bulk plasma is neither detected in the measured radiation nor in divertor heat loss. A 'core heating efficiency' $\eta$ can be defined accordingly as $\eta=\mathrm{P}_{\text {abs }} / \mathrm{P}_{\mathrm{L}}$, where $\mathrm{P}_{\mathrm{abs}}$ is the ICRF bulk power absorption. $\eta$ can be estimated in relative terms by comparing discharges, and in absolute terms by 
power balance analysis and comparisons with code simulations including the relevant wave collisionless damping mechanisms.

L-mode discharges at $\mathrm{B}_{\mathrm{T}}=2.7 \mathrm{~T}, \mathrm{I}_{\mathrm{p}}=2$ and $2.8 \mathrm{MA}$ were compared to further investigate the behaviour of $\eta$ [31]. ICRF power ramps up to $8 \mathrm{MW}$ were performed using $42 \mathrm{MHz}(\mathrm{H}) \mathrm{D}$ minority heating and various antenna toroidal phasings: $0 \pi 0 \pi$ (dipole), $0 \pi \pi 0,00 \pi \pi$ and 0000 (monopole), with respective dominant toroidal wavenumbers $6.4,4.2,2.7$ and $0 \mathrm{~m}^{-1}$ at the antennas. (Note that the $0 \pi \pi 0$ spectrum has an important secondary lobe near the main peak of the dipole one.) The analysis of these discharges confirmed earlier observations [32]: $\eta$ is maximum and typically $>90 \%$ in dipole $(0 \pi 0 \pi)$, but only about half as much in monopole $(0000)$ despite the much higher antenna coupling resistance. Also $\eta(0 \pi \pi 0)$ was $\sim 10$ to $20 \%$ less than $\eta(0 \pi 0 \pi)$, and $\eta(00 \pi \pi)$ was somewhat closer to $\eta(0000)$ than to $\eta(0 \pi 0 \pi)$. Note that a higher $\eta$ is obtained with the phasing with a higher wave single pass absorption $(0 \pi 0 \pi)$. Other experiments were carried out in which only part of each A2 array was fed. Interestingly, antennas with only one or two active in-phase straps had an $\eta 50 \%$ higher than the standard 0000 with four active straps.

In the FWHCD experiments reported in Section $5[30], \eta(0 \pi 0 \pi)$ was similar to that of hydrogen minority heating in $+90^{\circ}$. The heating efficiencies for $\pm 90^{\circ}$ FWCD phasings were $\eta\left(+90^{\circ}\right) \sim 0.6 \eta(0 \pi 0 \pi)$ and $\eta\left(-90^{\circ}\right) \sim 0.5 \eta(0 \pi 0 \pi)$, with a difference attributed to ${ }^{3} \mathrm{He}$ orbit pinch effects. Higher unaccounted power in $\pm 90^{\circ}$ phasings was correlated with lower single pass wave damping.

All the experiments confirm a strong dependence of the heating efficiency $\eta$ on the radiated parallel wavenumber spectrum; the observations are consistent with parasitic ICRF absorption by RF sheath voltage rectification [33], smaller unaccounted power being associated with the phasing producing the lowest rectified sheath potential. Note that if a weaker bulk power absorption $\mathrm{P}_{\mathrm{abs}}$ results in 
stronger sheath dissipation (due to the associated higher level of wave field amplitude at the sheaths), the higher single-pass wave absorption expected for monopole phasing on ITER might result in a reduction of parasitic sheath dissipation, hence in a better monopole heating efficiency than on JET. A stronger statement can unfortunately not be made on the basis of current knowledge.

The strong decrease of the heating efficiency accompanying a decrease of dominant radiated parallel wavenumber should duly be taken into account in the design of the ITER ICRF launcher, which will have similar phasing flexibility as the JET system. Indeed its operation in dipole phasing, for which one expects the maximum heating efficiency, is anticipated to have an insufficient or at best marginal antenna loading to deliver the nominal 20MW power at experimentally proven antenna maximum voltages, such as $\sim 33 \mathrm{kV}$ on JET. (This results from the loading estimates given in Fig. 2.1.3-3 of the ITER reference document [34] in the operating range 40-55MHz. More recent studies such as [35] have yet to be published; despite slightly higher loading predictions in dipole phasing they lead to the same conclusion regarding dipole operation.) Operation of the array with lower dominant wavenumbers such as in current drive $\left(90^{\circ}\right)$ or $00 \pi \pi$ phasings may provide sufficient antenna loading to deliver nominal power, but the concomitant lower heating efficiency should by no means be overlooked. The ability to model RF sheath dissipation phenomena is steadily improving (an interesting review can be found in [36]), but has not yet reached a level where the heating efficiency of a new antenna design could confidently be predicted. Therefore, in our opinion, the design of the ITER ICRF launcher should accomodate the reliable delivery of nominal power at maximum heating efficiency, i.e. in dipole phasing, in addition to the other phasings for which loading is more favourable but the heating efficiency reduced. For the estimated dipole loading, achieving this goal would require a strong reduction of the maximum antenna voltage, which could be done by attributing a second ITER port to ICRH and installing two antennas instead of the single one planned. 
This extension would also endow the system with wider operational margins, which is highly desirable to maximize its general reliability and the range of plasma equilibria to which it could deliver full power. However a thorough discussion of this broad issue lies outside the scope of the paper.

\section{Coupling studies during ELMs}

The strong antenna loading perturbations associated with ELMs induce large transient power reflection in the RF transmission systems, which triggers frequent protective RF power trips of the generators and severely limits the ICRF power delivered to ELMy H mode plasmas. ELM-resolved $\mathrm{RF}$ measurements on the antennas provide invaluable data to estimate the performance of future launchers [37]. Systematic observations of the perturbations of RF voltages associated with the rise of type I ELMs have shown that these perturbations propagate in the counter-current direction (the same direction as the electron diamagnetic drift), in agreement with the fast magnetic measurements. Typical toroidal velocities $\sim 200 \mathrm{~km} / \mathrm{s}$ (generally between 50 and $1200 \mathrm{~km} / \mathrm{s}$ ) are observed, corresponding to a toroidal period $\sim 120 \mu \mathrm{s}$. The highest velocities were seen in low density discharges. Therefore for most of the observed ELMs, the delays between antenna straps situated in the same toroidal octant should have marginal or negligible effect on the operation of the compensation networks of the ELM-resilient ICRF systems described in the next Sections.

\section{ELM tolerant matching proof of principle}


A prototype ELM-tolerant ICRF antenna matching system has been successfully tested at JET [38]. The technique is based on the same "conjugate T" (CT) matching circuit principle as proposed for ITER in $[39,40,41]$ and under implementation in the JET ITER-Like ICRF antenna (see section 9): The radiating antenna straps are connected pairwise in parallel through series matching elements. In [39] and on the JET ITER-Like system the latter are in-vessel matching capacitors; in the present proof of principle they are implemented as coaxial line stretchers located outside the tokamak vacuum vessel, like the alternative ITER ICRF design proposed in [40], [41]. At a baseline antenna loading (in absence of ELMs), the CT matching elements are adjusted to make the input reactive admittances of their two circuit branches cancel and to set the total input resistance to a low reference level. Further impedance transformation to the main power transmission line is achieved by a conventional variable stub and trombone tuner. Once the circuit is set in this configuration, a very low RF power reflection is maintained at its inputs during large increases of the antenna resistive loading such as occur during ELMs. More details on the characteristics and performances of CT circuits can be found in the above references and in [42].

In the JET proof of principle under consideration here the experimental setup involved one pair of adjacent straps of the A2 antenna array powered by a single RF amplifier. The tests fully confirm the feasibility of the matching scheme. Clear evidence of high load tolerance was observed during plasma sawtooth activity and ELMs, see Fig. 8. Reliable performance free of generator trips was demonstrated from 32 to $51 \mathrm{MHz}$. This approach appears a viable alternative to in-vessel matching schemes and offers additional advantages such as exclusive reliance on well-established coaxial line technology, manageable tuning accuracy requirements, separation of launching and matching subsystems, and capability to conjugate remote antenna straps. 


\section{Forthcoming enhancements to the JET ICRF system}

A major JET enhancement is under way with the scheduled installation of an additional ITER-like ICRF antenna in 2006 [43], shown on Fig. 9, which will be a key test of the ITER concept. It aims at validating novel antenna design principles in conditions as relevant as possible to ITER by coupling 7.2 MW to ELMy H-mode plasmas between 30 and $55 \mathrm{MHz}$. The high power density $\left(\approx 8 \mathrm{MW} / \mathrm{m}^{2}\right)$ is maximized by using poloidally short straps, and the resilience to fast varying RF loads by matching pairs of straps (in-vessel) in so-called conjugate-T circuits as described in section 8 . This is accompanied by the addition of $3 \mathrm{~dB}$ hybrid couplers in the transmission systems of two of the four existing A2 antennas, and a likely implementation of line stretcher conjugate T matching (see section 8) on the remaining two antennas. Concurrent use of these enhancements will allow a unique comparison of their performance. They will provide additional power for a wide range of conditions, in particular at low frequency (minority heating of ${ }^{3} \mathrm{He}$, second harmonic heating of $\mathrm{T}$, relevant to a future D-T campaign), and in presence of ELMs, further expanding the relevance of the JET ICRF system for ITER.

\section{Conclusions}

Several key ICRF physics issues relevant to a successful operation of ITER have been investigated on JET in 2003 and early 2004. Minority heating of helium three in hydrogen plasmas - $\left({ }^{3} \mathrm{He}\right) \mathrm{H}$ was systematically explored by varying the ${ }^{3} \mathrm{He}$ concentration and the toroidal phasing of the antenna 
arrays. The best heating performance (a maximum electron temperature of $6.2 \mathrm{keV}$ with $5 \mathrm{MW}$ of ICRF power) was obtained with a preferential wave launch in the direction of the plasma current. A clear experimental demonstration was made of the sharp and reproducible transition to the mode conversion heating regime when the ${ }^{3} \mathrm{He}$ concentration increases above $\sim 2 \%$. In the latter regime the best heating performance (a maximum electron temperature of $8 \mathrm{keV}$ with $5 \mathrm{MW}$ of ICRF power) was achieved with dipole array phasing, i.e. a toroidally symmetric antenna power spectrum. Minority heating of deuterium in hydrogen plasmas - (D)H - was also investigated but was found inaccessible, because this scenario is too sensitive to impurity ions with $\mathrm{Z} / \mathrm{A}=1 / 2$ such as $\mathrm{C}^{6+}$, small amounts of which directly lead into the mode conversion regime. The detailed investigation of these two ICRF scenarios in hydrogen plasmas seems to rule out usage of minority (D)H, but has demonstrated $\left({ }^{3} \mathrm{He}\right) \mathrm{H}$ as a reliable scenario for the heating of ITER plasmas during the low-activation phase of operations in hydrogen plasmas.

Minority heating of up to $3 \%$ of tritium in deuterium plasmas was systematically investigated during the JET Trace Tritium experimental campaign. This required operating JET at its highest possible magnetic field (3.9 to 4T) and its ICRF system at its lowest frequency (23MHz). The interest of this scenario for ICRF heating at these low concentrations and its efficiency at boosting the suprathermal neutron yield were confirmed, and the measured neutron and gammay ray spectra permit interesting comparisons with advanced ICRF code simulations.

The investigation of finite Larmor radius effects on the RF-induced high-energy tails during second harmonic $\left(\omega=2 \omega_{c}\right)$ heating of a hydrogen minority in D plasmas has demonstrated a strong decrease of the RF diffusion coefficient at proton energies $\sim 1 \mathrm{MeV}$, in agreement with theoretical expectations. Fast wave heating and current drive experiments in deuterium plasmas showed effective direct electron heating with dipole phasing of the antennas, but only small changes of the central plasma 
current density were observed with the directive phasings. New investigations of the heating efficiency of ICRF antennas confirmed its strong dependence on the parallel wavenumber spectrum, which should duly be taken into account when finalizing the ITER ICRF system design.

Significant advances have also been made in topics of a more technological nature, themselves equally strongly diven by the preparation for ITER: A new "conjugate T" ELM-tolerant antenna matching scheme, based on the same principle as proposed for the ITER ICRF system, has been given a first successful experimental demonstration. ELM studies using fast RF measurements indicate that the time delays between the loading perturbations induced by the ELMs on the various antenna straps should not significantly hamper operation of this matching scheme. The echnical enhancements planned on the JET ICRF system for 2006 should validate the concepts of high power density short-strap antenna arrays and load-tolerant conjugate T matching planned for ITER.

\section{Acknowledgments}

This work was conducted under the European Fusion Development Agreement. It is a pleasure to thank the staff who operated the JET tokamak, its heating systems and its diagnostics. The work carried out by the UKAEA personnel was jointly funded by the United Kingdom Engineering and Physical Sciences Research Council and by EURATOM. The work of E.L. is supported by the EU under a EURATOM Intra-European Fellowship. The constructive comments from the referees are gratefully acknowledged. 


\section{References}

[1] PAMELA, J., ONGENA, J. and JET EFDA Contributors, Nucl. Fusion 45 (2005) S63-S85.

[2] AYMAR, R., CHUYANOV, V., HUGUET, M., SHIMOMURA, Y., for the ITER Joint Central Team and Home Teams, ITER-FEAT - The Future International Burning Plasma Experiment Overview, in Fusion Energy 2000 (IAEA-CN-77, Proc. $18^{\text {th }}$ Int. Conf. Sorrento, 2000) (Vienna: IAEA) CD-ROM file OV/1 and http://www.iaea.org/programmes/ripc/physics/fec2000/html/node20.htm.

[3] BHAtnagaR, V.B., et al., Proc. $25^{\text {th }}$ EPS Conf. on Plasma Physics, Prague, Czech Republic (1998), ECA 22C (1998) 1178.

[4] GAMBIER, D.J., et al., Nucl. Fusion 30 (1990) 23-34.

[5] VAN EESTER, D., et al., in Radio Frequency Power in Plasmas, AIP Conf. Proceedings 694 (2004), Ed. C.B. Forest, Melville, New York.

[6] KIPTILY, V.G., et al., Nucl. Fusion 42 (2002) 999.

[7] KOROTKOV, A.A., GONDHALEKAR, A., STUART, A.J., Nucl. Fusion 37 (1997) 35.

[8] KAYE, A., et al., Fusion Engineering and Design 24 (1994) 1.

[9] CHEN, L., VACLAVIK, J., HAMMETT, G.W., Nucl. Fusion (1988) 28389.

[10] KOVANEN, M.A., CORE, W.G.F., HELLSTEN, T., Nucl. Fusion 32 (1992) 787.

[11] ERIKSSON, L.-G., et al., Phys. Rev. Letters 81 (1998) 1231-1234.

[12] MANTSINEN, M.J., et al., Nucl. Fusion 40 (2000) 1773.

[13] MANTSINEN, M.J., Phys. Rev. Letters 89 (2002) 115004. 
[14] MAYORAL, M.-L., LAMALLE, P.U., VAN EESTER, D., et al., in Radio Frequency Power in Plasmas, AIP Conf. Proc. 787 (2005) 122-129, Ed. S.J. Wukitch and P.T. Bonoli, Melville, New York.

[15] MAYORAL, M.-L., LAMALLE, P.U., VAN EESTER, D., et al., "Hydrogen plasmas with ICRF inverted minority heating and mode conversion regimes in the JET tokamak", submitted for publication in Nucl. Fusion.

[16] The JET and TFTR TEAMS, presented by D Start, Plasma Phys. Control. Fusion 40 (1998) A87.

[17] START, D.F.H., et al., Nucl. Fusion 39 (1999) 321.

[18] PHILLIPS, C.K., et al., Nucl. Fusion 40 (2000) 461-466.

[19]ZASTROW, K-D., et al., Proc. $31^{\text {st }}$ EPS Conf. on Plasma Physics, London, ECA 28G (2004).

[20] STORK, D., et al., in Fusion Energy 2004 (Proc. 20 ${ }^{\text {th }}$ Int. Conf., Vilamoura, 2004) (Vienna: IAEA) CD-ROM file OV/4-1 and http://www-naweb.iaea.org/napc/physics/fec/fec2004/datasets/index.html

[21]LAMAlle, P.U., MANTSINEN, M.J., et al., Proc. $31^{\text {st }}$ EPS Conf. on Plasma Physics, London, ECA 28G (2004) P-5.165.

[22] STORK, D., et al., Nucl. Fusion 45 (2005) S181.

[23] GIACOMELli, L., et al., Proc. $31^{\text {st }}$ EPS Conf. on Plasma Physics, London, ECA 28G (2004) P5-171.

[24] HEDIN, J., et al., Plasma Phys. Control. Fusion 40 (1998) 1085. 
[25] WILSON, J.R., et al., Phys. Rev. Letters 75 (1995) 842.

[26] KOROTKOV, A.A., GONDHALEKAR, A., STUART, A.J., Nucl. Fusion 37 (1997) 35.

[27]STIX, T. H., Nucl. Fusion 15 (1975) 737.

[28]CARLSSON, J., ERIKSSON, L.-G., HELLSTEN, T., Nucl. Fusion 37 (1997) 719.

[29] SALMI, A., et al., "JET Experiments to Assess the Clamping of Fast Ion Energy Distribution during ICRF heating due to Finite Larmor Radius Effects", to be submitted to Plasma Phys. Control. Fusion.

[30] HELLSTEN, T., LAXÅBACK. M., et al., Nucl. Fusion 45 (2005) 706-720.

[31] HEIKKINEN, J., et al., Proc. $31^{\text {st }}$ EPS Conf. on Plasma Physics, London, ECA 28G (2004) P-5.162.

[32] START, D.F.H., et al., AIP Conf. Proceedings 355 (1995) 7.

[33]D’IPPOLITO, D.A., MYRA, J.R., BURES, M., JACQUINOT, J., Plasma Phys. Control. Fusion 33 (1991) 607.

[34] ITER International Team, ITER Final Design Report 2001, Design Description Documents, Ion Cyclotron Heating and Current Drive System, WBS 5.1 (DDD), G 51 DDD 4 01-0719 W 0.2, July $\quad 2001, \quad$ see https://www.iter.org/ftp/ftp/fdr/DRG1latest/2001_FDR/fdr/fdr_index.html authorization).

[35] SWAIN, D.W., and CARTER, M.D., "ITER ICRF antenna loading with new limiter and plasma”, ITER International Team document G 51 RI 9 04-08-31 F 1, August 2004. 
[36] MYRA, J.R., D’IPPOLITO, D.A., RUSSELL, D.A., BERRY, L.A., JAEGER, E.F. and CARTER, M.D., in Radio Frequency Power in Plasmas, AIP Conf. Proceedings 787 (2005) 3, Ed. S.J. Wukitch and P.T. Bonoli, Melville, New York.

[37]BOBKOV, Vl.V., et al., Proc. $31^{\text {st }}$ EPS Conf. on Plasma Physics, London, ECA 28G (2004) P-1.141.

[38] MONAKHOV, I., et al., Fusion Eng. and Design 74 (2005) 467, Special Issue: Proc. $23^{\text {rd }}$ Symp. on Fusion Technology, Ed. F. Gnesotto, R. Piovan and M. Basso.

[39]BOSIA, G., Fusion Science and Technology 43 (2003) 153.

[40] MESSIAEN, A., et al., in Radio Frequency Power in Plasmas, AIP Conf. Proc. 694 (2004) 142, Ed. C.B. Forest, Melville, New York.

[41] DUMORTIER, P., et al., in Radio Frequency Power in Plasmas, AIP Conf. Proceedings 694 (2004) 94, Ed. C.B. Forest, Melville, New York.

[42] LAMAlle, P.U., MESSIAEN, A.M., DUMORTIER, P., DURODIÉ, F., EVRARD, M., LOUCHE, F., VERVIER, M. and WEYNANTS, R., in Radio Frequency Power in Plasmas, AIP Conf. Proceedings 787 (2005) 158, Ed. S.J. Wukitch and P.T. Bonoli, Melville, New York.

[43]DURODIÉ, F., et al., “The ITER-like ICRF Antenna for JET” , Fusion Eng. and Design 74 (2005) 223, Special Issue: Proc. $23^{\text {rd }}$ Symp. on Fusion Technology, Ed. F. Gnesotto, R. Piovan and M. Basso. 


\section{Figure captions}

FIG. 1. $\left({ }^{3} \mathrm{He}\right) \mathrm{H}$ minority heating at $\left.{ }^{3} \mathrm{He}\right]<1 \%$ with dipole, $+90^{\circ}$ and $-90^{\circ}$ antenna phasings (resp. blue, red and discontinuous black lines). Note the much higher neutron yield $\mathrm{R}_{\mathrm{NT}}$ achieved with $+90^{\circ}$.

FIG. 2. Time evolution of the $\gamma$-ray emissivity and ${ }^{3} \mathrm{He}$ concentration for three discharges, demonstrating disappearance of the fast ${ }^{3} \mathrm{He}$ population as $\left[{ }^{3} \mathrm{He}\right]$ was increased above $2 \%$.

FIG. 3. Response of the electron temperature to a $20 \mathrm{~Hz}$ modulation of the ICRF power in a discharge in which the ${ }^{3} \mathrm{He}$ concentration, $\left[{ }^{3} \mathrm{He}\right]$, was progressively increased from $\sim 0.8$ to $\sim 3.2 \%$ and modulation applied throughout. Before $\mathrm{t}=8.3 \mathrm{~s}$ and left inset: minority heating regime with indirect electron heating and no clearcut $\mathrm{T}_{\mathrm{e}}$ response; after $\mathrm{t}=8.3 \mathrm{~s}$ and right inset: mode conversion regime with direct electron heating and prompt $\mathrm{T}_{\mathrm{e}}$ response. The sharp transition between the two regimes occurs around $\mathrm{t}=8.3 \mathrm{~s}$ at $\left[{ }^{3} \mathrm{He}\right] \approx 2 \%$.

FIG. 4. Mode conversion heating regime with $2<\left[{ }^{3} \mathrm{He}\right]<4 \%$, dipole (continuous line) and $+90^{\circ}$ (broken line) antenna phasings. The ion-ion hybrid layer is located at $\mathrm{R} \approx 2.8 \mathrm{~m}$.

FIG. 5. Fundamental ICRF heating of minority tritium introduced by gas puff (23MHz, 4T). The T concentration is estimated $\sim 3 \%$ during the neutral beam (NBI) diagnostic pulses at $\mathrm{t}>9 \mathrm{~s}$. Maximum neutron yield $2.910^{16} / \mathrm{s}$, maximum coupled RF power $1.4 \mathrm{MW}$. 
FIG. 6. (a)D-T neutron emissivity profile at $\mathrm{t}=7.7 \mathrm{~s}$ for (T)D ICRF heating (dipole phasing, 23MHz). (b) fast $(\mathrm{E}>50 \mathrm{keV})$ triton midplane density simulated with the SELFO code for the same discharge (\#61280), showing contributions from passing, trapped and non-standard orbits. The T cyclotron layer is at $\mathrm{R} \approx 2.5 \mathrm{~m}$. The majority of $\mathrm{D}-\mathrm{T}$ neutrons originate from passing tritons. Their higher density on the HFS of the magnetic axis is due to the longer time spent there, and is in good agreement with the observed neutron profile.

FIG. 7. Perpendicular proton energy distributions measured with the NPA. Discharges \#58734 and 58738 respectively have $\mathrm{P}_{\mathrm{RF}}=5$ and $3 \mathrm{MW}, \mathrm{N}_{\mathrm{e} 0}=4$ and $3 \times 10^{19} \mathrm{~m}^{-3}$, hydrogen concentrations of order 3 and $4.5 \%, \mathrm{E}^{*} \sim 1.03$ and $1.37 \mathrm{MeV}$, similar absorbed powers per particle and similar fictitious effective tail temperatures $T_{\text {eff }}$ (see the discussion in the text).

FIG. 8. ICRF coupling to an ELMy plasma. The central diagram shows power $\mathrm{P}_{\mathrm{A}}$ delivered by one of the standard A2 antennas (the smoother curve is its time average over a moving 200ms window), exhibiting numerous generator trips. The lower trace shows the very steady power $\mathrm{P}_{\mathrm{C}}$ delivered by an antenna half (i.e. a pair of radiating straps) equipped with the prototype load resilient external conjugate $\mathrm{T}$ system.

FIG. 9. The JET ITER-like ICRF antenna. 


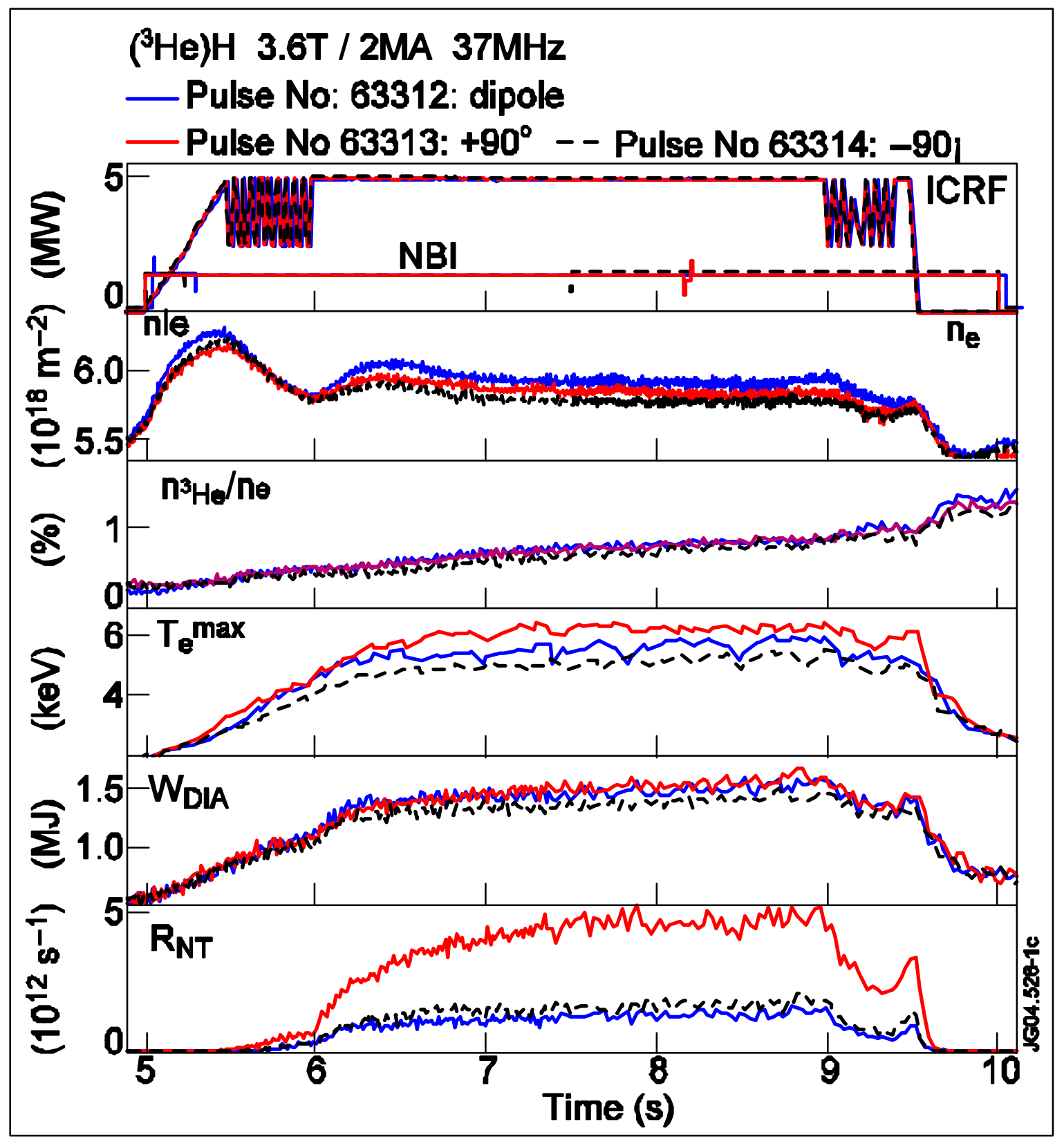

FIG. 1. $\left({ }^{3} \mathrm{He}\right) \mathrm{H}$ minority heating at $\left.{ }^{3} \mathrm{He}\right]<1 \%$ with dipole, $+90^{\circ}$ and $-90^{\circ}$ antenna phasings (resp. blue, red and discontinuous black lines). Note the much higher neutron yield $\mathrm{R}_{\mathrm{NT}}$ achieved with $+90^{\circ}$. 


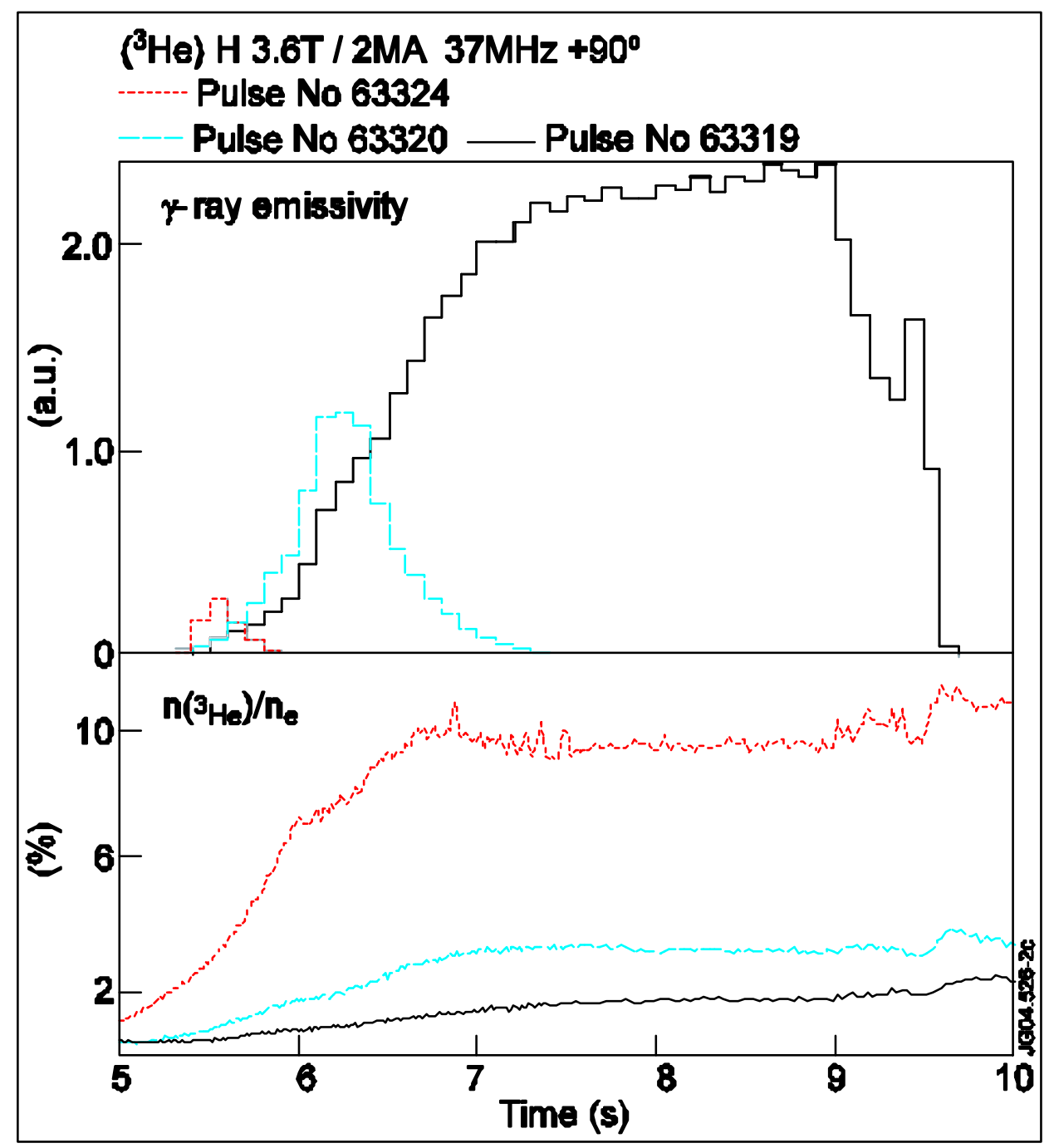

FIG. 2. Time evolution of the $\gamma$-ray emissivity and ${ }^{3} \mathrm{He}$ concentration for three discharges, demonstrating disappearance of the fast ${ }^{3} \mathrm{He}$ population as $\left[{ }^{3} \mathrm{He}\right]$ was increased above $2 \%$. 


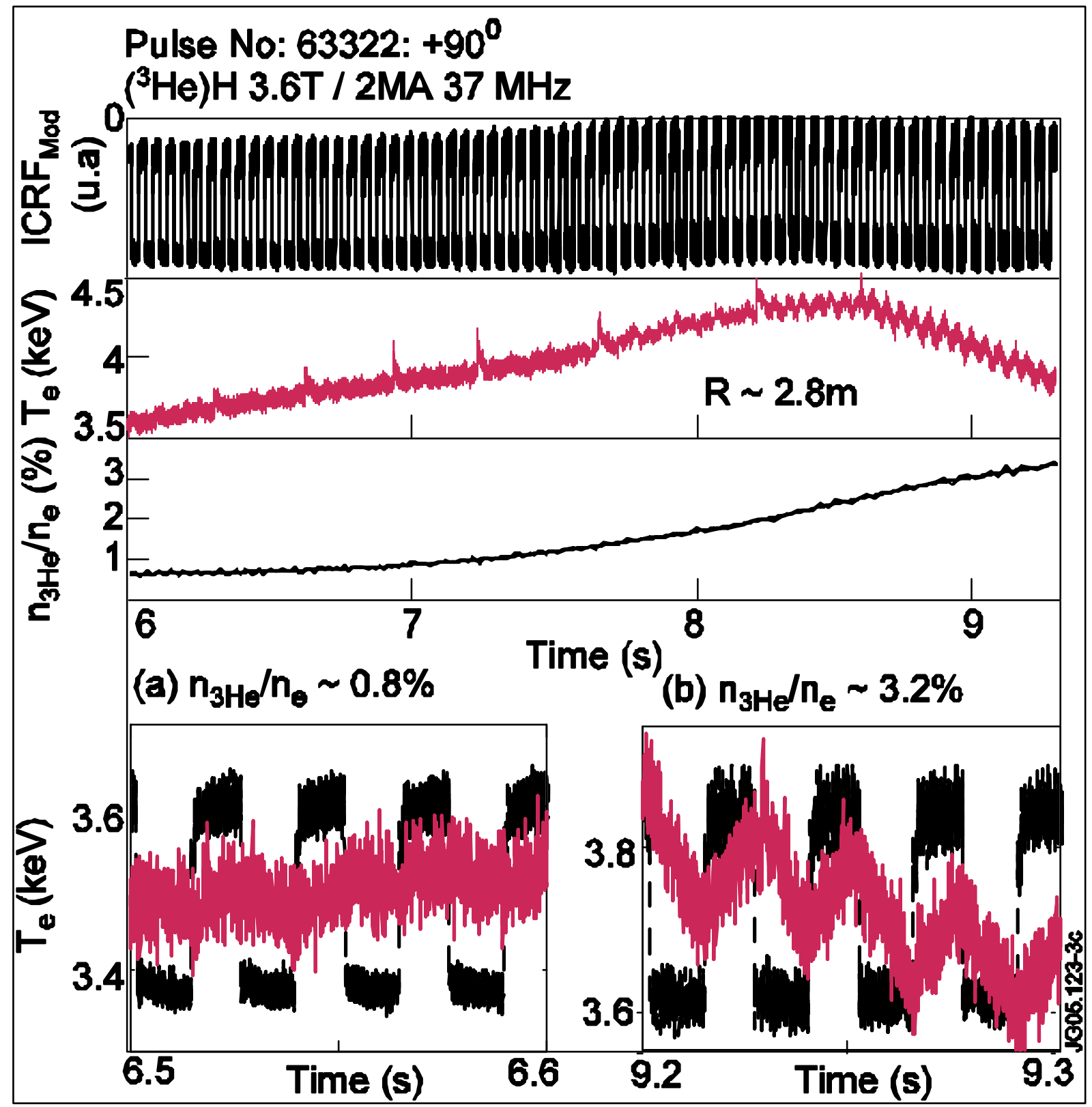

FIG. 3. Response of the electron temperature to a $20 \mathrm{~Hz}$ modulation of the ICRF power in a discharge in which the ${ }^{3} \mathrm{He}$ concentration, $\left[{ }^{3} \mathrm{He}\right]$, was progressively increased from $\sim 0.8$ to $\sim 3.2 \%$ and modulation applied throughout. Before $\mathrm{t}=8.3 \mathrm{~s}$ and left inset: minority heating regime with indirect electron heating and no clearcut $\mathrm{T}_{\mathrm{e}}$ response; after $\mathrm{t}=8.3 \mathrm{~s}$ and right inset: mode conversion regime 
with direct electron heating and prompt $\mathrm{T}_{\mathrm{e}}$ response. The sharp transition between the two regimes occurs around $\mathrm{t}=8.3 \mathrm{~s}$ at $\left[{ }^{3} \mathrm{He}\right] \approx 2 \%$.

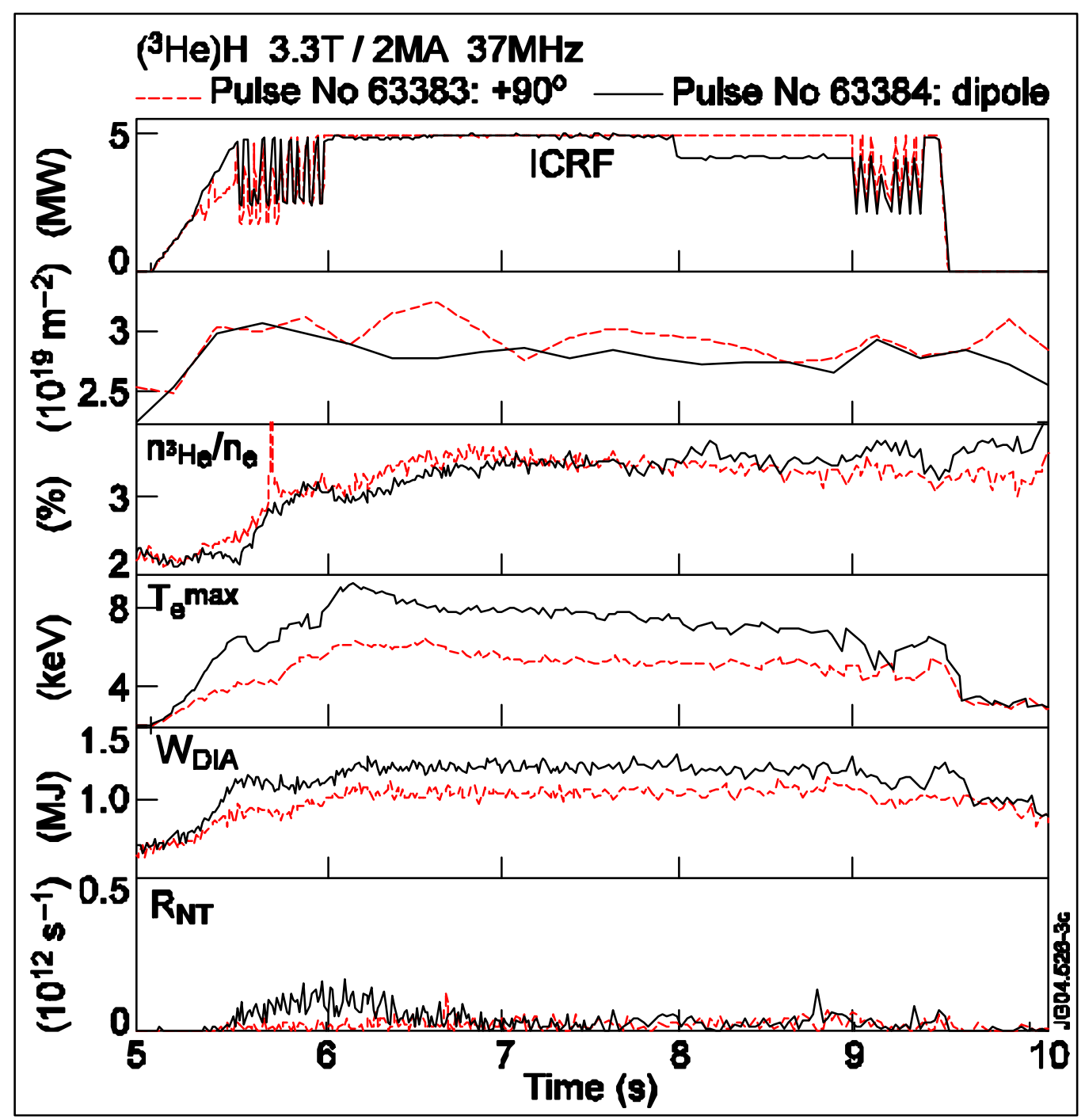

FIG. 4. Mode conversion heating regime with $2<\left[{ }^{3} \mathrm{He}\right]<4 \%$, dipole (continuous line) and $+90^{\circ}$ (broken line) antenna phasings. The ion-ion hybrid layer is located at $\mathrm{R} \approx 2.8 \mathrm{~m}$. 


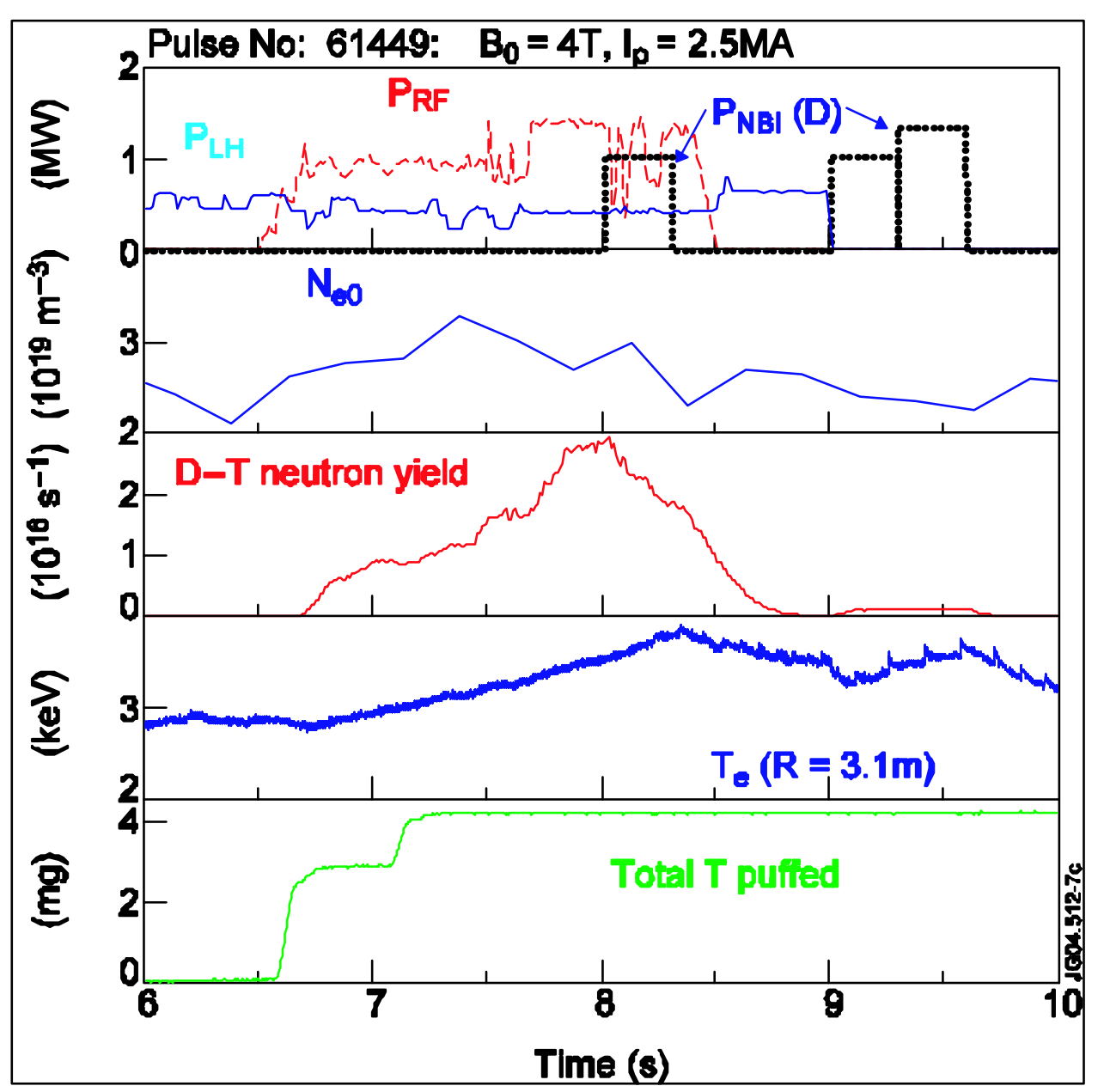

FIG. 5. Fundamental ICRF heating of minority tritium introduced by gas puff (23MHz, 4T). The T concentration is estimated $\sim 3 \%$ during the neutral beam (NBI) diagnostic pulses at $t>9$ s. Maximum neutron yield $2.910^{16} / \mathrm{s}$, maximum coupled RF power $1.4 \mathrm{MW}$. 
(a)

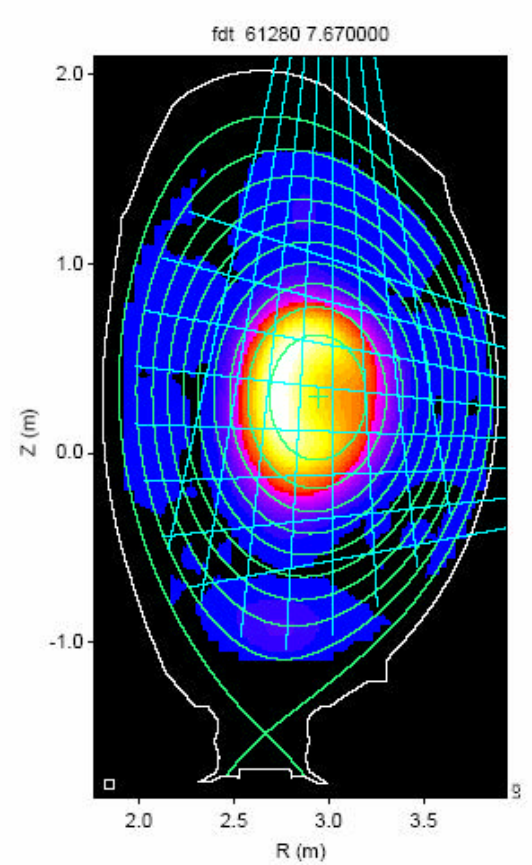

(b)

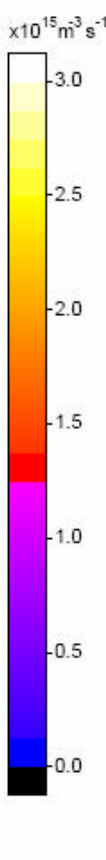

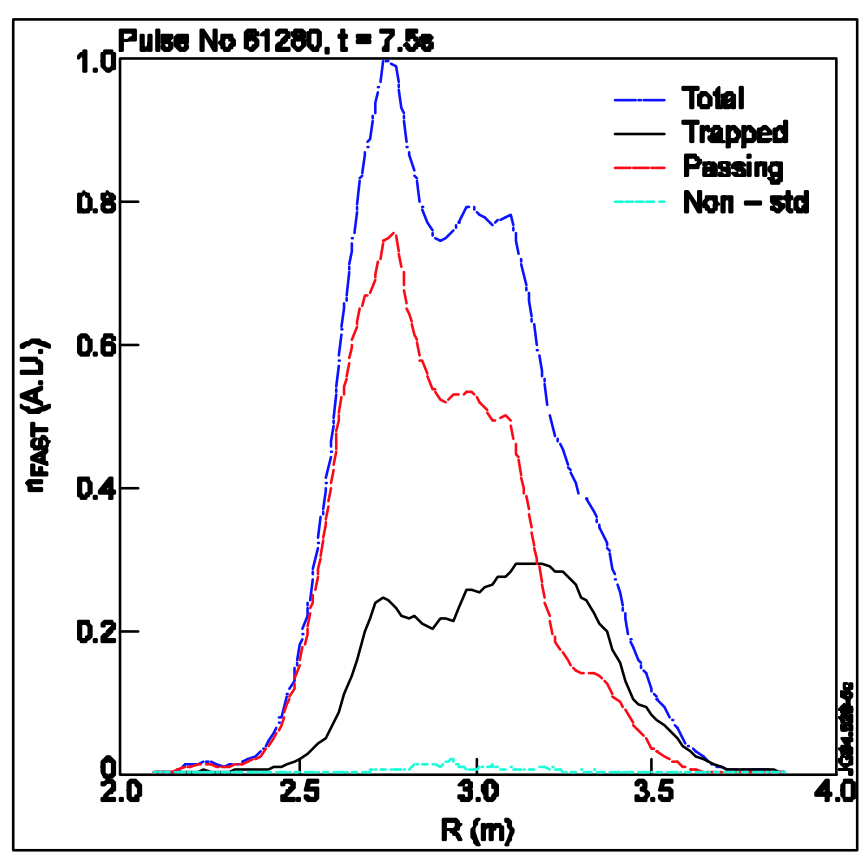

FIG. 6. (a) D-T neutron emissivity profile at $\mathrm{t}=7.7 \mathrm{~s}$ for (T)D ICRF heating (dipole phasing, 23MHz).

(b) fast $(\mathrm{E}>50 \mathrm{keV})$ triton midplane density simulated with the SELFO code for the same discharge (\#61280), showing contributions from passing, trapped and non-standard orbits. The T cyclotron layer is at $\mathrm{R} \approx 2.5 \mathrm{~m}$. The majority of $\mathrm{D}$ - $\mathrm{T}$ neutrons originate from passing tritons. Their higher density on the HFS of the magnetic axis is due to the longer time spent there, and is in good agreement with the observed neutron profile. 


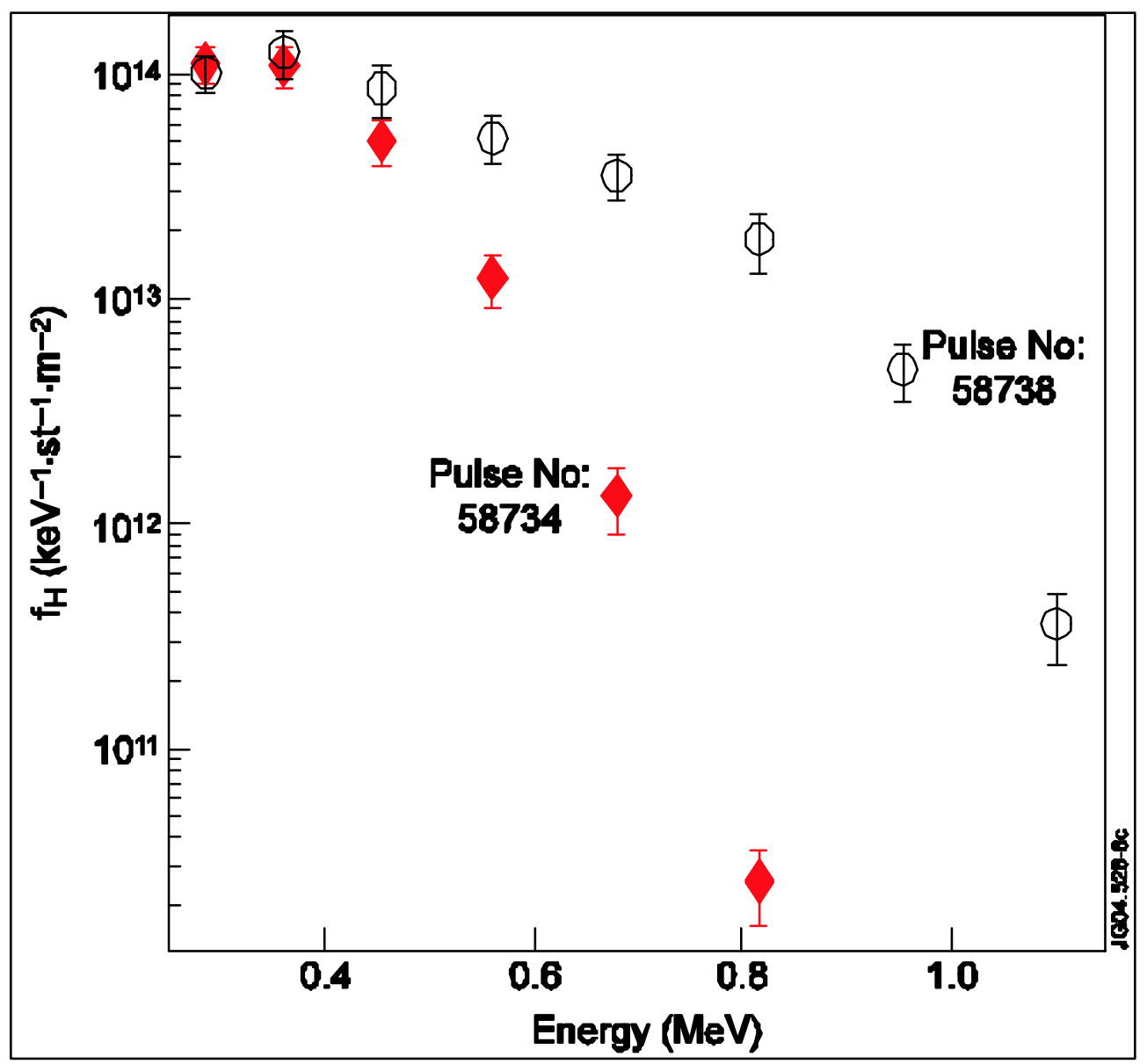

FIG. 7. Perpendicular proton energy distributions measured with the NPA. Discharges \#58734 and 58738 respectively have $\mathrm{P}_{\mathrm{RF}}=5$ and $3 \mathrm{MW}, \mathrm{N}_{\mathrm{e} 0}=4$ and $3 \times 10^{19} \mathrm{~m}^{-3}$, hydrogen concentrations of order 3 and $4.5 \%, \mathrm{E}^{*} \sim 1.03$ and $1.37 \mathrm{MeV}$, similar absorbed powers per particle and similar fictitious effective tail temperatures $T_{\text {eff }}$ (see the discussion in the text). 


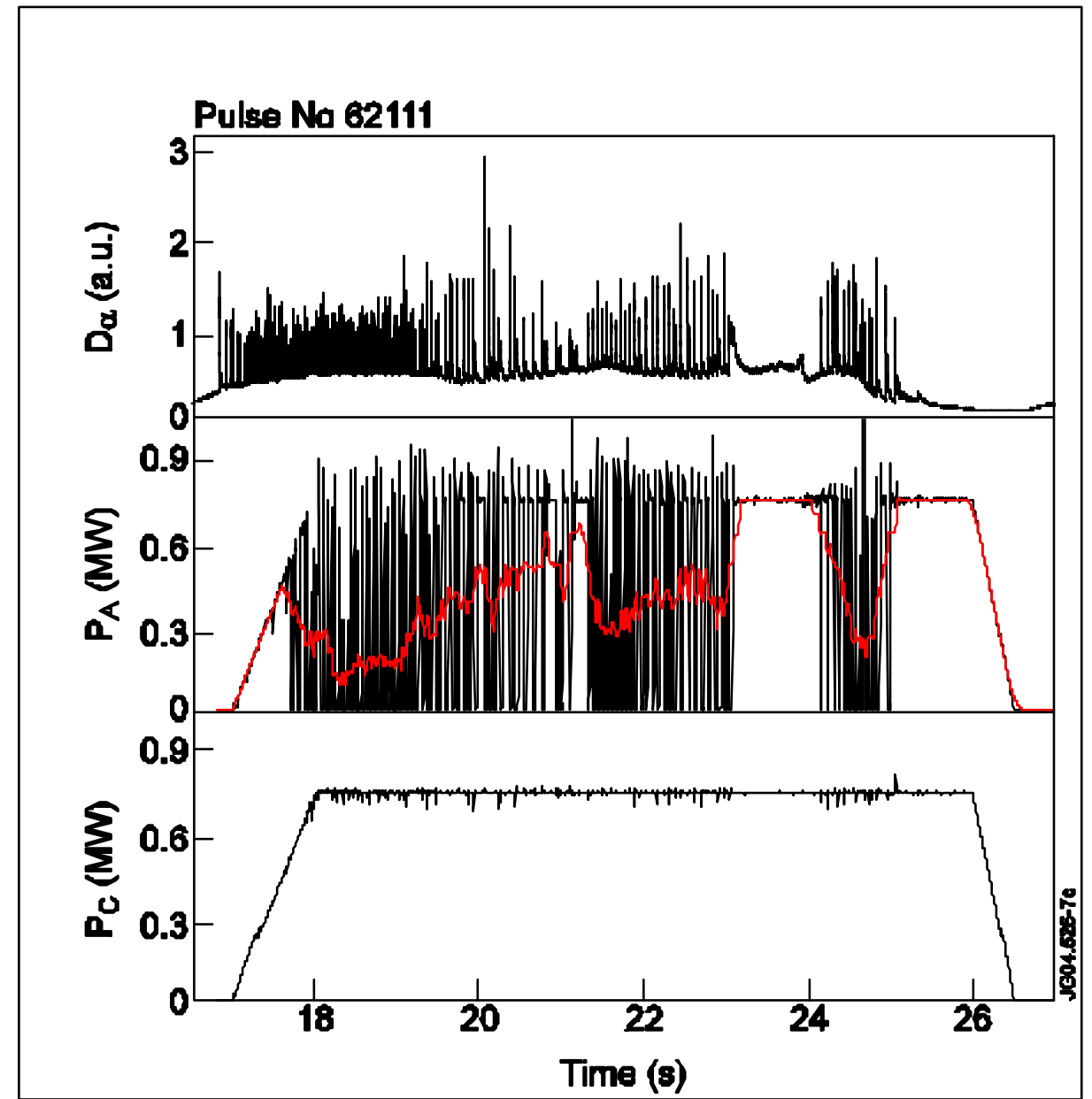

FIG. 8. ICRF coupling to an ELMy plasma. The central diagram shows power $\mathrm{P}_{\mathrm{A}}$ delivered by one of the standard A2 antennas (the smoother curve is its time average over a moving 200ms window), exhibiting numerous generator trips. The lower trace shows the very steady power $\mathrm{P}_{\mathrm{C}}$ delivered by an antenna half (i.e. a pair of radiating straps) equipped with the prototype load resilient external conjugate $\mathrm{T}$ system. 


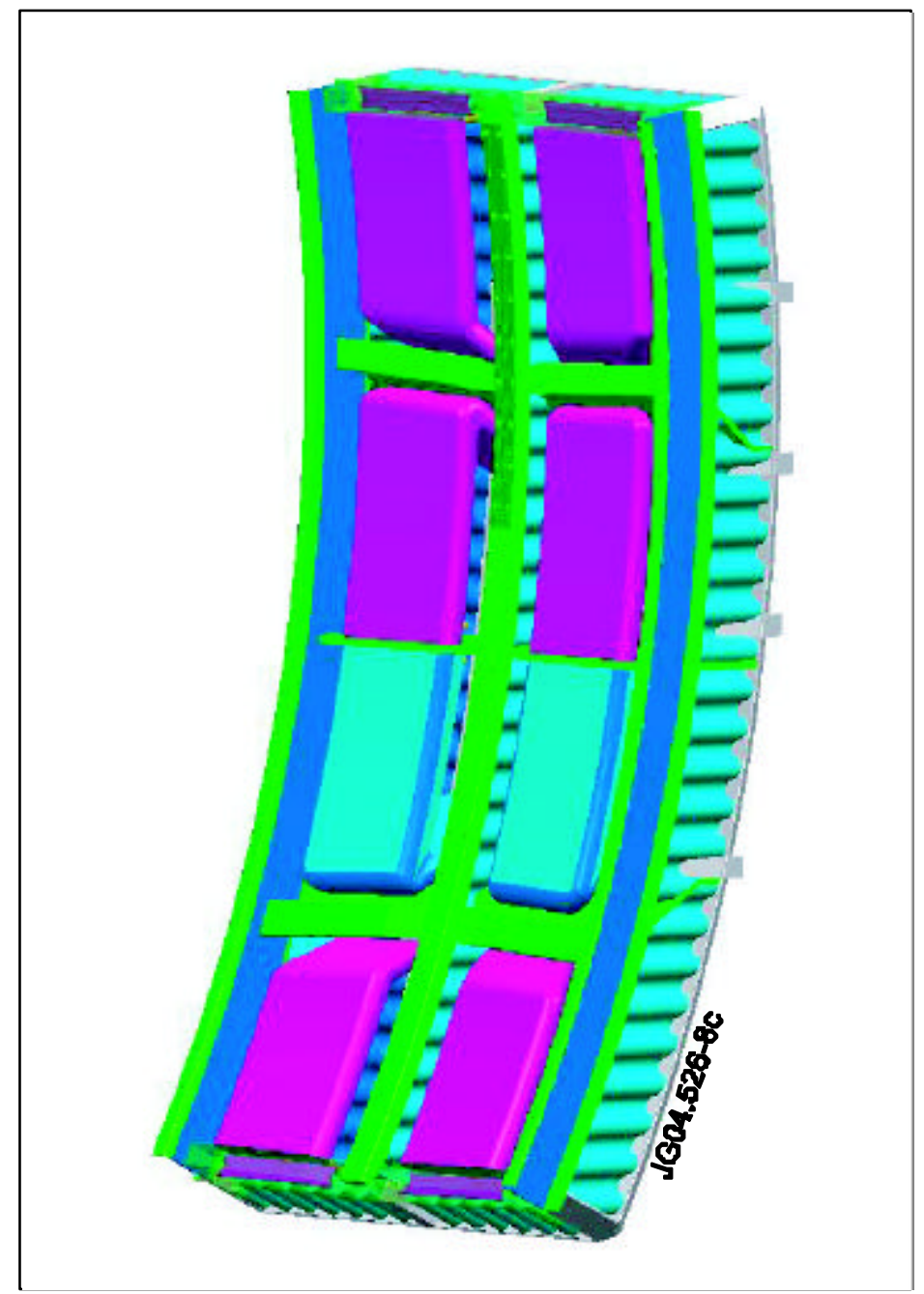

FIG. 9. The JET ITER-like ICRF antenna. 